\title{
Subject Teacher Conference as a Catalyst for Transformative Learning
}

\author{
Henny Soepriyanti*, Eka Fitriana, Udin Udin \\ Faculty of Education \\ School of Languages and Arts \\ University of Mataram \\ *untungwaluyo@unram.ac.id
}

\begin{abstract}
The West Nusa Tenggara Ministry of Education and Culture has made substantial efforts to revitalize the Subject Teachers Conference (STC) through various types of professional development programs, but these efforts are not well documented yet. Thus, its impact is not widely known among educators in the region. The implementation of STCs generally takes place routinely every year without any effort of the competent parties to evaluate its benefits and effectiveness. The current study aims to (1) describe the success factors of the STC as a catalyst for transformative learning among English teachers of junior high school in Sumbawa Regency, (2) outline the impact of transformative learning on the teachers' improved professionalism and uncover constraints faced by English teachers of junior high schools in practicing transformative learning gained from STC in their schools. The study employed a qualitative approach to account for teachers' developed transformative learning in STC. A qualitative research design with a multiple-case study approach was used as the basis for collecting, analyzing and comparing data from the field. This data was obtained through several activities in the field, such as focused group discussions, observations, and document studies. These data collected were analyzed using a thematic analysis approach. The research reveals most participants of the study experienced similar stages of transformative learning. The study concludes that the use of transformative learning in STC has facilitated the complete change of practices and provided teachers with new perspectives of learning.
\end{abstract}

Keywords: subject teachers conference, transformative learning, professional development

\section{INTRODUCTION}

In recent decades, education systems throughout the world have experienced significant developments in response to global changes in the economic, political and social fields [1, 2]. Many research publications on education in Indonesia show that education reform in Indonesia appears broadly related to the demands of globalization in all aspects of life [3]. With the rapidly growing economic conditions in neighboring countries, Indonesia is forced to improve its education system to be able to deal with such global changes. This phenomenon of globalization is seen as having put pressure on the demand for the preparation of reliable human resources in Indonesia so that they can compete internationally.
In facing the challenges above, the human resources in schools are urged to keep abreast of such a trend. In response to this issue, the Government of Indonesia (GoI) introduces a socalled Subject Teachers' Conference (termed as STC) nationwide. STC is a joint learning organization initiative facilitated by the Ministry of Education and Culture (MoEC) that provides subject teachers with on-going professional development. The purpose of establishing STC is to continuously support teachers to improve their professional competences and teaching performances. At this point, STC is expected to serve as a vehicle for learning together for subject teachers so that it impacts on the changes in their professional practices. By participating in the STC, teachers are expected to foster critical thinking in solving managerial and instructional problems they face in schools. Thus, in the long run, they will develop transformative learning that changes their approaches to the implementation of their professional jobs in schools.

So far, the incessant support of MoEC for providing teachers with on-going professional development through STC is unquestionably no doubt. MoEC has made many substantial efforts to revitalize the STC, by involving teachers in the inhouse training and in-service training activities, workshops, seminars, upgrading programs and so forth. Despite that, these efforts are not so well documented that their impacts are not widely known. The same is true with STCs in the province of West Nusa Tenggara. Generally, STC takes place routinely every year but the evaluation of its benefits and effectiveness is not available yet.

In searching for the previous studies on STC, the researchers found Sanda's [4] work on the role of STC in improving teachers' competences in an English language teacher. Sanda uses a purposive sampling technique to reveal the phenomenon to observe. The study concludes that English STC for Senior High Schools in OKU Regency contributed greatly to the development of teachers' professionalism of High School English Teachers in OKU Regency in terms of syllabus development, annual and semester programs, and lesson plans, developing innovative teaching methods and learning models, developing the use of teaching media and evaluation systems and increasing teacher professional competence. However, the management of STC still faced 
that learning is said to be transformative when learners are able to change their mindsets, thoughts, and beliefs about their practices. In dynamic organizations like schools, the changes of people' perspectives will provide a strong springboard for collective learning [16].

To foster transformative learning, Murphy and Fleming [17] suggest that adult learners employ dialogue as a medium for introducing and developing change and for shared learning. Through the dialogue, individuals can learn together to look at critically the common ground of current problems or issues. Thus, they will arrive at collective understanding. To build a profound dialogue the following conditions should be met: (1) communication openness among individuals, (2) courage to evaluate oneself (3) critical thinking and (4) equality in the dialogue. In this relation, Cranton and King [18] state that transformative learning occurs among individuals when they experience changes in the way they think; when they nurture critical thinking habits in seeking solutions to problems and when they jointly take actions to make changes in their organizations.

Although the STC initiative has been run more than three decades, so far there have not been many studies that look at its impact and contribution to teachers' change of practice. In West Nusa Tenggara, the researchers do not find any research reports about the impact of STC on the teachers' ability to transform learning outcomes gained from STC in the workplace. Due to limited information about this issue, various problems and/or obstacles faced by teachers participating in STC are not known. The objectives of the current study are, therefore, formulated as follows: (a) to describe the success factors of the STC as a catalyst for transformative learning among English teachers of junior high school in Sumbawa Regency; (b) to outline the impact of transformative learning on the teachers' improved professionalism; and (c) to uncover constraints faced by English teachers of junior high schools in practicing transformative learning gained from STC in their schools.

\section{METHODS}

This research study was conducted in Sumbawa Regency. The reason for choosing this site was that in general, the Sumbawa district had already developed an STC cluster in the city of Sumbawa Besar. Based on information from teachers in the location, the alumni of the teacher certification program have some kind of alumni association that became members of STC. At present this alumni association has a substantial role in helping to revitalize the STC in this place. The alumni of the certification program had played an active role in the routine STC activities. For that reason, therefore, the researchers wanted to explore further how teachers used STC as a medium of change for themselves and their peers.

For this study, the research team made an inventory of the list of junior secondary teachers in Sumbawa Regency who attended STC socialization and training. STC groups were selected in the city of Sumbawa Besar whose members consisted of junior high school teachers who actively participated in the STC as a joint learning forum. 
This data is then displayed, reduced, concluded and verified with other data. All data sources were matched with other data sources using data triangulation techniques. Finally, the data were then grouped and sorted according to the themes that emerged. Data relevant to the theme were grouped into subthemes until they saturated [22].

\section{FINDINGS}

In general, the discussion of the results of this study focused on analyzing the data obtained through interviews with various parties as mentioned above. To classify the data obtained, researchers used a thematic analysis model. The first part presents an analysis of data from various sources related to success factors that make STC a catalyst for transformative learners among teachers participating in regular STC meetings. There are 3 big themes emerge from the data, namely: (1) shared discomfort feelings, (2) learning shared reflection and (3) the emergence of joint action. The following discussion outlines the impact of transformative learning on increasing the professionalism of teachers in carrying out their professional duties. There are 2 major themes obtained from the data, namely (1) the emergence of a new understanding of the STC, and (2) the functioning of the STC as a catalyst for changing professional teacher education practices. The last section explains the results of data analysis related to problems, challenges and obstacles faced by English teachers participating in STC.

The first theme is related to the emergence of a so-called collective pain. The data analysis revealed that each teacher had different reasons why they participated in the STC. A great number of participants explained that at first, they were reluctant to participate in the STC. They said that the forum made them experience feelings of shame and fear because they considered that their shortcomings in teaching were discussed openly. For example, Teacher-03 stated that he felt uncomfortable speaking in front of a group of teachers she was not familiar with. Similarly, Teacher-01 explained that he felt more or less the same. He felt uncomfortable when he was asked to give examples of his teaching habits in front of other STC participants. He said, "I felt uncomfortable and embarrassed when I first joined the STC. I assume that I feel the dumbest among those present" In the same case Teacher-02 explained his thoughts as follows: "I remember when the first time I joined STC, I was very embarrassed ... when I was asked to outline the steps of using a scientific approach for teaching English, one of my colleagues commented on my shortcomings. I felt as if I was humiliated. I feel myself very stupid because of that comment".

Most STC participants felt that the input from their colleagues was a criticism that attacked them personally. Teacher-08 mentioned the beginning of participating in STC activities as an unforgettable bad experience. This experience made him choose to remain silent not to speak in the STC for some time. He said, "I am not actively speaking in the forum because I do not want my weaknesses to be discussed at the STC meeting". 
The data above shows that the open dialogue in the STC was seen as a threat by the participants. They considered that the dialogue in STC meetings made them lose self-esteem. In the same vein, some teachers admitted that at the beginning of their participation in the STC they chose to refrain from being active in the routine dialogue as they felt shocked by the new experiences. These findings indicate that the participants experienced the same feeling in addressing the conversation in the STC. They see the shared learning model introduced by the STC team as a vehicle for learning had unlocked their selfdeficiencies and weaknesses of others.

Furthermore, the second theme that emerged from the data was related to the occurrence of critical reflection from participants after they were actively involved in the STC a few months later. Data from the interviews showed that six out of 10 teachers acknowledged the emergence of a critical reflection process after they were actively involved in the STC. Teacher04 explained that he was aware of his shortcomings in teaching because of his limited teaching skills. He claimed that he had participated in teacher capacity building training provided by the local education office but it was not as routine as STC. Due to the top-down model of training, his participation in the training was on a preform basis. He did not have an opportunity to participate in the dialogue like what he got in STC. Therefore, he never knew the development of his teaching ability. He stated, "at STC I am free to ask if I do not understand and senior friends want to listen to our complaints" He also thinks that his colleagues wanted to allow every STC participants to learn to teach new ways to teach English. He concluded, "Before we joined STC, we had to teach in our way. We did not know much about the development of the latest English teaching techniques. We never communicated with other teacher members in our area".

The third theme was related to the emergence of joint actions. In this case, some informants explained that after going through difficult times to adapt to the STC, they began to get used to the dialogue together as a medium for collective learning. With the emergence of shared understanding and shared learning, most teachers claimed that they experienced changes in their views and attitudes towards dialogue in the STC. At this point, teacher- 03 commented: "We are starting to miss criticism from peers" According to Teacher-08, regular meetings at STC made teachers want to learn to listen to feedback and criticism from others. Teacher-4 explained that STC had become a joint forum that supported her to achieve learning outcomes more optimally. She commented, "After a few months of participation, I began to get used to enjoying dialogue and how to learn together in STC".

Teacher-07 described the STC as a forum for learning from others. He stated that the teachers had given him strong motivation to work better in the team because "our colleagues appreciated our efforts and when we have shortcomings, we discuss them improve our capacity" In his view, the STC provided a balanced evaluation of the strengths and weaknesses of the participants. "I like interacting with my colleagues at STC because they encourage me to share any ideas and experiences". Teacher-08 considered that open communication between all STC participants had opened his perspectives to value the opinions of others. Both participants suggested that the STC continue to be strengthened to encourage English teachers to learn in a better direction and increase communication with fellow teachers in the research site. All of these data show that the STC has successfully empowered and strengthened the participants' capabilities to try out new things in their teaching practices.

As a consequence of the emergence of joint learning actions, a number of English teachers often conducted informal talks with their peers outside the STC activities. They exchanged ideas about learning experiences at STC or listened to the aspirations of their peers. These teachers admitted that such informal encounters were very useful for them to get the missing information due to their absence from STC. For example, Teacher-05 stated that he used to meet his colleagues at his school during break time to get information about learning models from his colleagues who attended STC. "I must seek information about new things that I don't know yet," said Teacher-03. Overall, the findings signify teachers' serious intentions to learn from their peers. This continually increases over time.

The data above provides evidence that most participants are increasingly critical of their learning outcomes in the STC. Changes in perception of the role of dialogue as a medium for learning are seen in the data. The following quote expresses a general feeling among teachers: "The critical reflection session has encouraged us to become introspective and make a critical connection between our past teaching habits and the present situation" By critically assessing their past experiences, these teachers were able to explore issues related to their shortcomings of teaching practices in the past. The findings of this study show that participants develop a critical assessment of their teaching practices. Through this critical reflection, they were able to explore and find ways to understand the complexity of their teaching duties.

There are 2 major themes obtained from the data related to the impact of transformative learning on improving the professionalism of English Middle School (SMP) teachers in Sumbawa Regency, namely (1) the emergence of new initiatives to implement student-focused teaching-learning and (2) changes in teacher teaching practices. Related to the first theme, observations in a number of classes indicate that teachers developed teaching initiatives based on the learning outcomes they received from their peers at STC. The result of observation in 8th grade at SMP-02 has proved that the teacher was creatively using learning media. To explain the topics covered, the teacher used cartoon film as learning media to encourage students to work collaboratively. Initially, students were assigned to work in small teams. Later, together they explored some of the vocabularies in the film. The teacher gave questions and provides opportunities for students to discuss and share their understanding of the cartoon film.

From observations in other classes, the results were obtained that the teacher developed interactive teaching initiatives as they obtained from the STC. In SMP-01, for example, teacher-03 developed learning activities with a 
Other obstacles that arise from the data are the existence of several STC clusters that are not going well due to lack of resource personnel, remote locations, lack of government funding and lack of support from the school. Several teachers claimed that they spent their own money to attend the STC. "We are aware that there is no search for knowledge without cost," said Teacher01. These positive changes in perspective have the potential to strengthen the capacity of teachers to implement the K-2013 curriculum.

\section{CONCLUSION}

This study found several success factors of STC as a catalyst that supports teacher's transformative learning. The phases of joint pain and collective learning have a positive impact on changes in the way teachers view teaching English. The process of dialogue and shared pain in the STC has encouraged teachers to experience changes in perspective and changes in teaching practices. Through STC they think of new alternative actions. As a consequence of collective learning outcomes, the changes produced by teacher's experience convergence.

The study results also reveal effective ways to encourage teachers to improve their teaching performance. In general, it can be concluded that STC has become a catalyst for joint learning that has an impact on increasing the capacity of teachers in teaching in their fields. They develop transformative learning and ways of working collectively with others after they have gained useful knowledge and skills from STC. Through their participation in reflective dialogue at STC, participants get the opportunity to learn to take collective actions to overcome pedagogical problems. In principle, STC has given them not only the motivation to achieve better teaching achievement but also a place to establish communication in their field of science with colleagues from various schools.

Problems, challenges, and obstacles were identified to arise due to several reasons, such as (1) the number of teaching loads given by the principal, (2) the official demand of 24-hour teaching hours for every teacher and (4) some STC clusters did not run well due to the lack of resource personnel, remote locations, lack of government funding, and lack of support from schools.

\section{ACKNOWLEDGMENT}

The authors gratefully acknowledge the DIPA BLU research grant 2019 the University of Mataram. Indonesia.

\section{REFERENCES} show that not all teachers were capable of changing their teaching practices. The data show that many teachers still faced difficulty in applying the use of a scientific approach in the teaching of English. Even though they tried their best, passive interactions still occurred in some classes. Teachers who were not actively participated in STC tended to work alone and teach in a teacher-centered way. The researchers noted that some teachers in some classes spent a lot of time explaining grammar and not providing enough time for oral practice.
[1] F. Rizvi and R. Lingard, Globalizing Education Policy. New York: Routledge, 2010.

[2] J. Chen and Rutgers University. Graduate School-New Brunswick. Globalization, democratization, and government education provision in East Asia, 2007.

[3] P. Cranton, A transformative perspective on the Scholarship of Teaching and Learning. Higher Education Research and Development 30, 75-86, 2011. 
[13] J. Mezirow and E.W. Taylor, Transformative Learning in Practice: Insights from Community, Workplace, and Higher Education. San Francisco: Jossey Bass, 2009.

[14] J. Mezirow and Associates, Learning as transformation: Critical perspectives on a theory in progress (J. Mezirow, Ed.). San Francisco: Jossey-Bass, 2000.

[15] J. Mezirow, Fostering critical reflection in adulthood: A guide to transformative and emancipatory learning. San Francisco: Jossey-Bass Publishers, 1990.

[16] A. Brockbank, I. McGill and N. Beech, Reflective learning in practice. Aldershot, UK: Gower Publishing Ltd., 2002.

[17] M. Murphy and T. Fleming, 'The Application of the Ideas of Habermas to Adult Learning. In P. Sutherland \& J. Crowther (Eds.), Lifelong Learning: Concepts and Contexts (pp. 48-57). London: Routledge, 2006.

[18] P. Cranton and K.P. King, "Transformative Learning as a Professional Development Goal," New Directions for Adult and Continuing Education, vol. 2003, no. 98, pp. 31-38, 2003.

[19] K.F. Punch, Introduction to Research Methods in Education. London: Sage Publications, 2009.

[20] J.W. Creswell, Research Design: Qualitative, Quantitative, and Mixed Methods Approaches. Thousand Oaks, CA, Sage Publications, Inc., 2003.

[21] S.B. Merriam, Case study research in education: A qualitative approach (Rev. ed.). San Francisco: Jossey-Bass, 1998.

[22] M.B. Miles and A.M. Huberman, Qualitative data analysis: An expanded sourcebook. Thousand Oaks: Sage, 2005.

[12] M. Rismark and A.M. Salvberg, "Knowledge Sharing in Schools: A Key to Developing Professional Learning Communities," World Journal of Education, vol. 1, no. 2, pp. 150-160, 2011. 